\title{
Students' cognitive barrier in problem solving: Picture-based problem-solving
}

\author{
A. Wilda Indra Nanna ${ }^{1}$, Enditiyas Pratiwi ${ }^{1}$ \\ ${ }^{1}$ Universitas Borneo Tarakan, Indonesia \\ $\square$ wiradjab@gmail.com
}

\author{
Article Information \\ Submitted January 01, 2020 \\ Revised April 15, 2020 \\ Accepted May 07, 2020
}

\section{Keywords}

Cognitive Barrier;

Fraction Mathematics;

Problem-Solving.

\begin{abstract}
Pre-service teachers in primary education often have difficulty in solving mathematical problems, specifically fractions that are presented with a picture. In solving problems, some thought processes are needed by the teacher to reduce students' cognitive barriers. Therefore, this study aimed to reveal the cognitive barriers experienced by students in solving fraction problems. The cognitive barriers referred to in this study are ways of thinking about structures or mathematical objects that are appropriate in one situation and not appropriate in another situation. This study employed a descriptive-qualitative method. Furthermore, participants were followed up with in-depth semi-structured interviews to find out the cognitive barriers that occurred in solving fraction problems. This study discovers that the participants, in solving fraction problems, experienced all indicators of cognitive barrier and two cognitive obstacles are found as new findings that tend to involve mathematical calculations and violates the rules in dividing images into equal parts in the problem-solving procedure.
\end{abstract}

\section{INTRODUCTION}

Students practice various forms of thinking activities that aim to develop their different cognitive structures in the process of learning mathematics (Antonijević, 2016). The cognitive structure can be developed if the instructor's knowledge to teach mathematics or so-called the pedagogical content knowledge is sufficient. Besides the factors that come from the teachers, learning barriers can also be experienced by students in various levels of ability (Fuadiah, 2015). In the process of learning mathematics, problem-solving serves as the basis for starting and practicing a variety of mathematical thinking activities.

Various thought operations are carried out in solving mathematical problems and understanding mathematical content and thinking activities that occur as part of conceptual and procedural understanding (Swanson \& Williams, 2014). This activity allows the development of mathematical cognitive structures in which it allows the occurrence of errors that cannot be predicted, called barrier (Fuadiah, 2015). Errors in solving problems can be one barrier to constructing knowledge. Errors are something fundamental and positive in the learning process (Idris \& Narayanan, 2011). In the process of constructing knowledge, students can gain new knowledge and some obstacles will enrich their learning experience through the process of thinking and cognitive conflict that occurs in the students' minds. Students almost always face resistance as part of the thinking process in every learning process (Brown, 2008). One of the activities that can be done by teachers so that the thought process can be developed is by knowing the cognitive barriers of students.

Cognitive barriers are ways of thinking about mathematical structures or objects that are appropriate in one situation and not appropriate in another situation (Herscovics, 2019).

$\begin{array}{ll}\text { FHow to cite } & \text { Nanna, A. W. I., \& Pratiwi, E. (2020). Students' cognitive barrier in problem solving: Picture-based problem- } \\ & \text { Solving. Al-Jabar: Jurnal Pendidikan Matematika, 11(1), 73-82. } \\ \text { E-ISSN } & \text { 2540-7562 } \\ \text { Published by } & \text { Mathematics Education Department, UIN Raden Intan Lampung. }\end{array}$


problems within a certain time. The knowledge leads to the mind but when faced with new problems, the knowledge possessed is proven to be inadequate and difficult to adapt (Nyikahadzoyi et al., 2013). There is a reason to believe that fundamental obstacles arise from the fact that certain concepts have a level of complexity that makes it necessary to know certain orders (Tall, 1989). For example, a fraction is more complicated than integers, and experience with operations on integers will lead to cognitive barriers when individuals try to complete operations on the fraction. One might hypothesize that students' cognitive barriers are the result of previous experiences and their internal processes in the experience.

Types of cognitive barriers can be identified through (1) a tendency to rely on intuitive experiences that cannot be trusted; (2) tendency to generalize; and (3) barriers caused by natural language (Herscovics, 2019). By knowing these cognitive barriers, teachers can provide highquality learning (improved teaching and the process of building knowledge) for all students (Nyikahadzoyi et al., 2013). Cornu in (Tall, 2002) distinguishes cognitive barriers into four types: genetic barriers, psychological barriers, didactic barriers, and epistemological barriers. Interestingly, cognitive barriers are known to help to identify difficulties experienced by students in the learning process and determining appropriate teaching strategies, especially epistemological barriers.

Based on the opinions of the experts, the researchers focused this study on revealing cognitive barriers that occur when students solve fraction problems. Some researchers have conducted research related to cognitive barriers in learning the concept of a fraction (Antonijević, 2016; Bentley \& Bossé, 2018; Yoshida \& Sawano, 2002), but there are no studies that discuss cognitive barriers in determining fraction values based on images. Research on fractions at the college level reveals that students still have misconceptions in solving mathematical problems (Abdullah et al., 2015; Alghazo \& Alghazo, 2017; Bentley \& Bossé, 2018; Siegler et al., 2013; Tian \& Siegler, 2017). Therefore, it is considered important to do because the students of the Elementary School Teacher Education (PGSD) Study Program consider fractions as material that is difficult to understand and solve. This study was aimed to reveal the cognitive barriers experienced by PGSD students in solving fraction problems. The objective of the PGSD Study Program is to prepare elementary school (SD) teachers, in which fractions are one of the materials that must be taught properly.

\section{METHODS}

This study employed the qualitative method to reveal cognitive barriers experienced by students in solving fraction problems. The cognitive barriers referred to in research are ways of thinking about structures or mathematical objects that are appropriate in one situation and not appropriate in another situation. To describe cognitive barriers experienced by students, the researchers used three indicators, they are the tendency to rely on intuitive experiences that cannot be trusted, the tendency to generalize, and the obstacles caused by natural language.

The instrument of this study was the researcher himself to reveal students' cognitive barriers using question sheets, observation of problem-solving processes, and in-depth semistructured interviews. The potential participants of this study were 46 PGSD students who had taken the Number Concept course. In this study, they were asked to solve fraction problems in the form of images that determined the fraction values. The potential participants who had the right and wrong answers and were different from other potential participants were selected to 
be the participants of the study. The participants who were chosen were followed up through in-depth semi-structured interviews. In this study, only one participant met the criteria because 45 other potential participants had the same answer (all true or all false). The main data in this study was the result of the participant's answers confirmed through the triangulation process using the results of in-depth semi-structured interviews and observations.

\section{RESULTS AND DISCUSSION}

This section describes the cognitive barriers experienced by Agustinus (A) in solving four fraction problems (three problems were given in the form of pictures and one problem was given in the form of description problems). A determined the fractional value of the image shown in Figure 1.

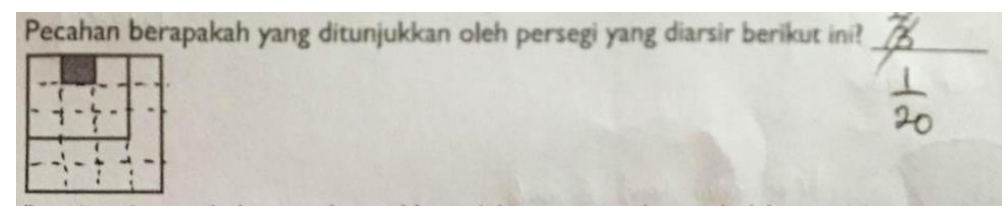

Figure 1. Problem 1 and A's Answer. Source: (Amerika, n.d.)

Based on the picture above, A determined the fractional value through the following stages:

1. Directly saw one part of the whole so that it determined the fractional value as $\frac{1}{3}$.

2. Corrected his answer by stating that the image did not show the fractional value.

3. A realized that the definition of the fraction was an equal part of a whole.

4. Then A assumed when the parts in the picture were made into the same part, then the shaded part showed the fractional value.

5. A used helpline to divide the image into equal parts.

6. A found that the given image shows a fractional value of $\frac{1}{20}$.

This is supported by the results of the interview shown in Table 1.

Table 1. Answer Confirmation

\begin{tabular}{ll}
\hline \multicolumn{1}{c}{ Researchers } & \multicolumn{1}{c}{ A } \\
\hline How did you solve the fraction problem? & $\begin{array}{l}\text { First, I immediately saw the picture given showing } \\
\text { the fraction of } \frac{1}{3} . \text { However, a few moments later I } \\
\text { was doubtful about that answer. }\end{array}$ \\
Because in the picture, there were three parts but the \\
parts were not the same. So, this is not a fraction.
\end{tabular}

A quickly realized the wrong answer was made. In the first problem, the cognitive barriers almost occurred but A overcame them. The process experienced by A is relevant to the results of the study by Antonijević (2016) which says that this process occurs because of the use of prior knowledge and experience in solving certain problems. This is also consistent with the results of research that says students have the same misconceptions as elementary school students in solving fraction problems (Bentley \& Bossé, 2018). If the levels of problems are 
increased, then it is possible to develop and increase the capacity of mathematical thinking. Based on Figure 1, it can be said that A did not experience cognitive barriers even though there was a tendency to generalize the concept found in the given fraction problem. A determined the fractional value of the picture shown in Figure 2.

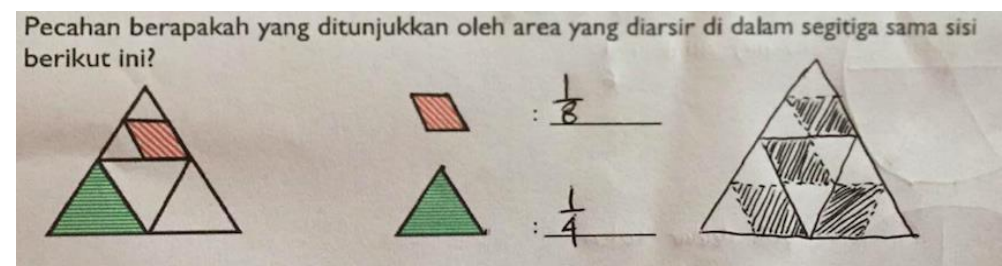

Figure 2. The Second Problem and A's Answer. Source: (Amerika, n.d.)

Based on the picture above, A determined the fractional value through the following stages:

1. In the red-shaded image, A looked at the picture showing a fractional value of $\frac{1}{2}$.

2. However, in the figure, there are four triangles with the same sizes so that the original fraction value of $\frac{1}{2}$ became $\frac{1}{8}$.

3. In the green-shaded image, A looked at the picture showing the fractional value of $\frac{1}{4}$.

This is supported by the results of the interview shown in Table 2.

Table 2. Answer Confirmation

\begin{tabular}{cc}
\hline Researchers & A \\
\hline How did you solve the fraction problem? & First, I saw a picture shaded in red showing a
\end{tabular}
fractional value of $\frac{1}{2}$. Then I realized that there were four triangles with the same sizes so I corrected the answer to $\frac{1}{8}$.

Why was the answer changed from $\frac{1}{2}$ to $\frac{1}{8}$ ?

Then, how did you find $\frac{1}{8}$ ?

What about the fractional value in the green shading?

Are you sure?
Because I saw that there are $\frac{1}{2} \mathrm{in} \frac{1}{4}$.

I multiplied the $\frac{1}{2}$ and $\frac{1}{4}$. Besides, I did a doublecheck using the helplines to divide the image into equal parts. I divided the same triangles according to the red shading.

$\frac{1}{4}$, ma'am.

Yes ma'am. Because there was one part that was shaded from four equal parts.

In the re-checking process carried out by $\mathrm{A}$, there was a process of dividing the image into equal parts. The process of dividing was carried out by A by dividing three existing triangles with the same shapes as in one triangle with red shading. In this process, A ignored the mathematical rule of dividing a fraction by equal parts. This is consistent with the statement that one of the causes of cognitive barriers is an error due to mismatched steps in the procedure to resolve the problem (Perbowo \& Anjarwati, 2017). One cause of cognitive impairment is an unusual focus on mathematical procedures (Nyikahadzoyi et al., 2013). The final answer was corrected but the steps used in solving problems violated the mathematical rules. Also, A got the final answer through the multiplication operation process on the part with the red shading against the whole parts. To confirm the answer, A drew the fraction based on the multiplication operation with Figure 2. This is consistent with the results of the study which says that students 
can represent fractions in the form of images but cannot represent the concept of fraction multiplications into the form of images correctly (Faradiba et al., 2019). Based on Figure 2, A tended to generalize the concepts so that the initial concept that had already owned cannot be directly used. A determined the fractional value of the picture shown in Figure 3.

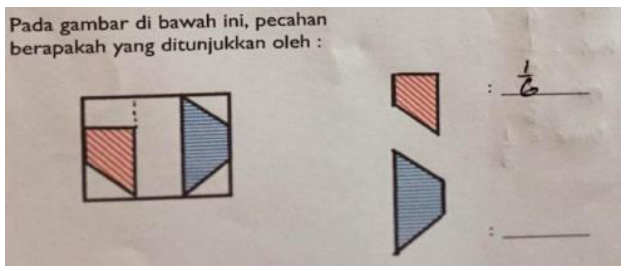

Figure 3. Problem 3 and Answer A. Source:(Amerika, n.d.)

Based on the picture above, A determined the fractional value through the following stages:

1. In the red-shaded area, A looked at the picture that showed the fractional value of $\frac{1}{6}$.

2. In the blue-shaded area, A could not find the value of the fraction.

This is supported by the results of the interview shown in Table 3 .

Table 3. Answer Confirmation

\begin{tabular}{|c|c|}
\hline Researchers & $\mathbf{A}$ \\
\hline How did you solve the given fraction problem? & $\begin{array}{l}\text { I saw the picture. It was is divided into three equal } \\
\text { parts. In one part, I saw the fraction of the red- } \\
\text { shaded are was } \frac{1}{2} \text {. }\end{array}$ \\
\hline $\begin{array}{l}\text { How did you determine that the red-shaded are } \\
\text { was } \frac{1}{2} \text { ? }\end{array}$ & $\begin{array}{l}\text { Because the parts that were not shaded, if they are } \\
\text { put together, will have the same size as the red- } \\
\text { shaded area. }\end{array}$ \\
\hline $\begin{array}{l}\text { But, on the answer sheet, you wrote that the } \\
\text { fraction of the red-shaded was } \frac{1}{6} \text {. Can you explain } \\
\text { it? }\end{array}$ & $\begin{array}{l}\text { Yes ma'am, because } \frac{1}{2} \text { was in } \frac{1}{3} \text {. Through the } \\
\text { multiplication operation, the value obtained was } \frac{1}{6} \text {. }\end{array}$ \\
\hline Why there was no answer to the blue-shaded area? & $\begin{array}{l}\text { I was confused, ma'am. In one part that contained } \\
\text { the blue shading, It could be divided into equal } \\
\text { parts, neither } \frac{1}{2} \text { nor } \frac{1}{3} \text {. }\end{array}$ \\
\hline $\begin{array}{l}\text { Were you sure the blue-shaded area can't be } \\
\text { resolved? }\end{array}$ & (thinking and trying to doodle) \\
\hline What are you doing? & I am trying to divide the image, ma'am. \\
\hline $\begin{array}{l}\text { You found the answer for the red-shaded is, did } \\
\text { you use the same way to find the answer? }\end{array}$ & $\begin{array}{l}\text { Yes, ma'am, but I did not get it. Because the part } \\
\text { of the blue-shaded was not the same as the rest. }\end{array}$ \\
\hline $\begin{array}{l}\text { Why did you focus on dividing based on the blue- } \\
\text { shaded area? }\end{array}$ & $\begin{array}{l}\text { So, can I divide the blue-shaded area into smaller } \\
\text { parts? }\end{array}$ \\
\hline d it if you tried & (tried) \\
\hline Got it? & $\begin{array}{l}\text { Yes, ma'am, I got it. The red-shaded area was also } \\
\text { the same. I got a fraction of } \frac{1}{6} \text { or } \frac{3}{18} \text {, so the blue- } \\
\text { shaded area should be } \frac{4}{18} \text { or } \frac{2}{9} \text {. }\end{array}$ \\
\hline
\end{tabular}

The red-shaded area in Figure 3 could be solved by A by dividing the image into three equal parts. A saw one part that was not shaded. If it was combined, it would have the same shape as the red-shaded area. After that, A performed the multiplication operation of the redshaded area with the whole parts. Previously in Figure 2, A did the same procedure and was able to find the answer. Unfortunately, in Figure 3, he didn't re-check the answer. This is in line 
with the results of a study which says that the resulting image implies that there are a fraction in the process and the fraction as processes must be interrelated (Herman et al., 2004).

The blue-shaded area in Figure 3 could not be found by A, whereas in Figure 1, A was able to overcome the cognitive barriers that occur slightly. In Figure 2, A did not experience cognitive barriers at all but did an error in the fractional problem-solving procedure. In Figure 3 , with the same problem-solving procedure, A should have been able to find the fractional value of the blue-shaded area. This is contrary to the results of research which says that if a given problem continues to be developed with various micro-cognitive mathematical structures (abilities, skills, knowledge, etc.) then it is possible to develop and increase the capacity of thinking (Antonijević, 2016). This condition occurred because of an error in the fractional problem-solving procedure in the completion of Figure 2, so that in the blue-shaded area in Figure 3 cannot be resolved.

Interventions in fraction learning are needed because cognitive barriers are always experienced by prospective teachers (Osana \& Royea, 2011). Besides, several successful interventions provide hope for increasing knowledge of fractions for students (Tian \& Siegler, 2017). This is consistent with the results of the research. During the interview, A could determine the fraction value through the intervention by the researchers. The following picture was produced by A after the intervention.

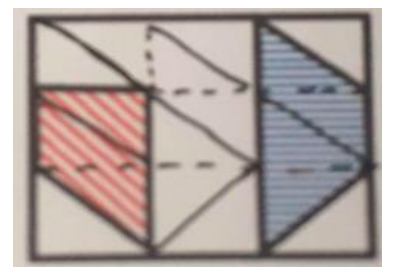

Figure 4. A's Answer after the Intervention

A determined the fractional value of the following problem.

Ms. Ayu distributed two omelets to 6 children, Lely, Yaya, Dani, Kiko, Gia, and Binar. The first omelet was divided equally among the 6 children. The second omelet was also the same where every child got the same portion. However, because Gia felt full, she decided to give her share to Binar. Kiko also felt full so he gave his share to Lely and Dani. Describe the number of omelets own by each child!

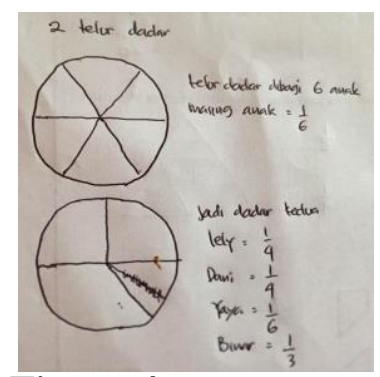

Figure 4. A's Answer

Based on the problem, A solved the fractional problem through the following stages:

1. A drew an omelet in a square shape and divided it into 6 equal parts.

2. He corrected his answers by changing it into a circle.

3. The first omelet picture was divided into 6 equal parts.

4. For the second omelet picture, A immediately divided the image into 4 unequal parts.

5. In determining the second image, A used the division operation. 
This is supported by the results of the interview shown in Table 4 .

Table 4. Answer Confirmation

Researchers
How did you solve the problem given?
What did you find after reading the question for the
second time?
second time?

How did you finally find the circle divided into six equal sizes?

What about the second omelet?

Why did you divide it into unequal parts?

How do you determine the parts?

Can you explain it?

How did you draw the second omelet?

Then what about the picture?

Does your drawing show the fractional value of Yes

each part?

If other people interpret your drawings, is it (thinking)

possible to find out the value of the fraction of each part?

How's that?

Initially, I drew a square and then divided it into 6 parts. Because it was difficult, I read the question again.

It turns out that the object was an omelet, so I drew it into a circle. For the first picture, I divided it into 6 parts because there were 6 children and each child got the same portions. However, I had difficulty in dividing the circle into six equal sizes. I kept trying, more or less, three times. Finally, I got the picture I wanted.

For the second picture, I divided it into 4

Unequal parts.

I divided it based on the parts obtained by each child.

By dividing it, ma'am.

Gia did not get a share because it was given to Binar for $\frac{1}{6}$. Kiko also did not get a share because it was given to Leny and Dani, each got $\frac{1}{12}$.

Yaya $\operatorname{got} \frac{1}{6}$, the size was the same as the first picture. Binar $\operatorname{got} \frac{1}{6}$ From Gia, then the portion became $\frac{1}{3}$. Leny and Dani got $\frac{1}{12}$ each from Kiko, so their share became $\frac{1}{4}$.

(show picture)

(Wrote the name of the child in each section)

The fourth problem given by researchers was a problem in the form of story problems. The fourth problem was designed to have a higher level of thinking when compared to the first problem to the third. The researcher applied the results of a study that says that if a given problem continues to be developed with various micro-cognitive mathematical structures (abilities, skills, knowledge, etc.) then it is possible to develop and increase the capacity of thinking (Antonijević, 2016). If you see the result done by A, the answer was correct. However, in the process of problem-solving, there are cognitive barriers in the form of relying on intuitive experiences that cannot be trusted and obstacles caused by natural language. The intuitive experience in question is that A always assumed that to solve the fraction problems in the form of an image, the image must be rectangular while the context of the problem given was an omelet that normally circular. Although intuitive experience is still controversial in finding the truth, it turns out that quite a lot is involved and helps mathematicians in mathematics (Sukmana, 2011). Based on this theory, the intuitive experience can be useful if it is appropriate 
to the real context and targeted interventions are needed to rearrange students' intuitive experiences.

A's assumption to solve fraction problems in the form of images by making rectangular images is a cognitive barrier caused by natural language. Errors are divided into two different categories, namely language problems, and problems in the problem-solving process (Prakitipong \& Nakamura, 2006). The natural language of the given problems did not affect A's thought process, thus, the information on the problem was ignored. Suyitno (2008) interprets the language and logic of mathematics. The result is that mathematical logic and language are very closely intertwined. While A, in understanding the problem, did not involve logic, so cognitive barriers occurred.

Also, in solving the fourth problem, a involved counting operations to determine the size of each person's share. A did a mathematical calculation and then described the parts of the question. This condition shows that all this time, a thought to solve a mathematical problem through mathematical calculations. It was influenced by the previously solved problems while the fourth problem was in the non-routine form of problem that could be solved directly without going through mathematical calculation procedures. Students tend to prefer assignments in the form of routine questions and there is a possibility of a student interpreting non-routine questions as the routine one, besides, they are confident that non-routine tasks are more suitable to be completed using the routine assignment approach (Jäder et al., 2017). Other research results state that the provision of non-routine tasks can be a trigger for the emergence of students' creative thinking and actions while routine tasks can hinder students' creative thinking processes (Beghetto, 2017).

\section{CONCLUSIONS}

Based on the results of the study, the subject experienced all three cognitive barriers namely, relying on intuitive experiences that cannot be trusted, the tendency to generalize, and obstacles caused by natural language. Also, other cognitive barriers that occurred was the tendency to use mathematical calculations to determine the fractional value of the image. After that, the subject checked the answer using the lines in the picture to make sure the results of the calculated operations performed correctly. Another cognitive barrier in this study was that the subject saw the shaded part as part of dividing the whole into equal parts. Also, the shaded and the unshaded parts, according to the subject, must have the same shape or size. If it cannot be imagined in the same shape or size, the subject could not solve the problem. This condition is an error in the procedure of solving problems that violate the rules in dividing the image into equal parts.

This study has several limitations. The first limitation is that the researchers did not adjust the problems given and the problems that have been received by the students in the lecturing process. The students are still used to solving routine problems. It is suggested for further researchers to reveal whether students who are accustomed to solving non-routine form fraction problems still experience cognitive barriers. The second limitation is that the data was taken from one class while there were other classes taught by different lecturers with a possibly different methods of problem-solving. Further researchers can compare cognitive barriers experienced by students with different fraction learning methods. 


\section{AUTHOR CONTRIBUTIONS STATEMENT}

AWIN worked as the principal investigator for this research project. The study was designed, conceptualized and carried out by him. She had major contribution in devising theoretical framework and reviewing literature pertaining to the study. EP had been an integral part of the whole process from brainstorming to writing her input has always been important. She played an important role in data collection and analysis.

\section{REFERENCES}

Abdullah, A. H., Abidin, N. L. Z., \& Ali, M. (2015). Analysis of students' errors in solving higher order thinking skills (HOTS) problems for the topic of fraction. Asian Social Science, 11(21), 133-142.

Alghazo, Y. M., \& Alghazo, R. (2017). Exploring common misconceptions and errors about fractions among college students in Saudi Arabia. International Education Studies, 10(4), 133.

Amerika, D. R. (n.d.). USAID prioritas: Mengutamakan pembaharuan, inovasi, dan kesempatan bagi guru, tenaga kependidikan, dan siswa.

Antonijević, R. (2016). Cognitive activities in solving mathematical tasks: The role of a cognitive obstacle. Eurasia Journal of Mathematics, Science and Technology Education, 12(9), 2503-2515.

Beghetto, R. A. (2017). Lesson unplanning: Toward transforming routine tasks into non-routine problems. ZDM - Mathematics Education, 49(7), 987-993.

Bentley, B., \& Bossé, M. J. (2018). College students' understanding of fraction operations. International Electronic Journal of Mathematics Education, 13(3), 233-247.

Brown, S. A. (2008). Exploring epistemological obstacles to the development of mathematics induction. The 11th Conference for Research on Undergraduate Mathematics Education, $1-19$.

Faradiba, R., Susiswo, S., \& As'ari, A. R. (2019). Representasi visual dalam menyelesaikan masalah pecahan. Jurnal Pendidikan: Teori, Penelitian, \& Pengembangan Journal of Education, 4(7), 885-891.

Fuadiah, N. F. (2015). Me-43 epistemological obstacles on mathematic's learning in junior high school students: A study on the operations of integer material. May, 17-19.

Herman, J., Ilucova, L., Kremsova, V., Pribyl, J., Ruppeldtova, J., Simpson, A., Stehlikova, N., Sulista, M., \& Ulrychova, M. (2004). Images of fractions as processes and images of fractions in processes. Psychology, 4, 249-256.

Herscovics, N. (2019). Cognitive obstacles encountered in the learning of algebra. In Research Issues in the Learning and Teaching of Algebra.

Idris, N., \& Narayanan, L. M. (2011). Error patterns in addition and subtraction of fractions among form two students. Journal of Mathematics Education, 4(2), 35-54.

Jäder, J., Sidenvall, J., \& Sumpter, L. (2017). Students' mathematical reasoning and beliefs in non-routine task solving. International Journal of Science and Mathematics Education, 15(4), 759-776.

Nyikahadzoyi, M. R., Mapuwei, T., \& Chinyoka, M. (2013). Some cognitive obstacles faced by "a" level mathematics students in understanding inequalities: A case study of bindura 
urban high schools. International Journal of Academic Research in Progressive Education and Development.

Osana, H. P., \& Royea, D. A. (2011). Obstacles and challenges in preservice teachers' explorations with fractions: A view from a small-scale intervention study. Journal of Mathematical Behavior, 30(4), 333-352.

Perbowo, K. S., \& Anjarwati, R. (2017). Analysis of students' learning obstacles on learning invers function material. Infinity Journal, 6(2), 169.

Prakitipong, N., \& Nakamura, S. (2006). Analysis of mathematics performance of grade five students in Thailand using Newman procedure. Journal of International Cooperation ..., 9(1), 111-122.

Siegler, R. S., Fazio, L. K., Bailey, D. H., \& Zhou, X. (2013). Fractions: The new frontier for theories of numerical development. Trends in Cognitive Sciences, 17(1), 13-19.

Sukmana, A. (2011). Profil berpikir intuitif matematik. Profil Berpikir Intuitif Matematik, 155 .

Suyitno, H. (2008). Hubungan antara bahasa dengan logika dan matematika menurut pemikiran Wittgenstein. Humaniora, 20(1), 26-37.

Swanson, D., \& Williams, J. (2014). Making abstract mathematics concrete in and out of school. Educational Studies in Mathematics, 86(2), 193-209.

Tall, D. (1989). New cognitive obstacles in a technological paradigm. 92, 87-92.

Tall, D. (2002). The psychology of advanced mathematical thinking. In Advanced Mathematical Thinking.

Tian, J., \& Siegler, R. S. (2017). Fractions learning in children with mathematics difficulties. Journal of Learning Disabilities, 50(6), 614-620.

Yoshida, H., \& Sawano, K. (2002). Overcoming cognitive obstacles in learning fractions: Equal-partitioning and equal-whole. Japanese Psychological Research, 44(4), 183-195. 